Volume 5, Issue S1 (2020), pp. 35-41

Journal of School Administration Research and Development

ISSN: 2470-8496 Print/ ISSN: 2470-850X Online

ojed.org/jsard

\title{
Dual Credit Compliance Issues with COVID-19
}

\author{
Alexandrea Horton \\ Governors State University, USA
}

\begin{abstract}
High school leaders are facing new challenges regarding dual credit programs and the COVID-19 emergency. Conflicting with traditional instructional procedures, school reopening policies have many high schools implementing various remote learning modalities of instruction. High school leaders must adjust their dual credit university partnership procedures to reflect these new conditions, ensuring students and instructors have access to necessary technology resources.
\end{abstract}

Keywords: COVID-19, dual credit, instruction, technology

Education institutions nationwide are challenged to implement remote education procedures due to the COVID-19 emergency. In Illinois, for example, the governor issued an executive order on March 13, 2020, requiring all public and nonpublic schools to suspend face-to-face instruction until March 30, 2020. Subsequent executive orders extended the suspension of face-to-face instruction through the remainder of the 2020 school year. This sudden shift to remote learning has challenged students and instructors of dual credit courses who lacked the technological support to continue meeting college expectations for instruction through remote instructional platforms (Illinois Board of Higher Education, Illinois Community College Board, \& Illinois State Board of Education, 2020). Stakeholders were conflicted over which institution was 
primarily responsible for ensuring that dual credit students and instructors were afforded the necessary resources and materials to continue a rigorous, collegelevel curriculum in the absence of face-to-face instruction. This challenge must be addressed promptly, as dual credit students may already be suffering the repercussions of missed instruction and inaccessible course materials that would have been delivered in a face-to-face class.

On March 20, 2020, the U.S. Department of Education's Office of Postsecondary Education announced policy adaptations underlined as guidance for interruptions of study related to COVID-19. These policies addressed how higher education institutions must comply with Title IV and Higher Education Act policies. The policy compliances detailed were expected to be applied for students whose academic activities were either directly or indirectly impacted by COVID-19. This ensured that schools provided flexibility when working to help students complete the academic term in which they were enrolled (Office of Postsecondary Education, 2020). The Office of Postsecondary Education announced that the policy adaptation will be applied to students enrolled in dual credit courses, as their course grade will be reflected on their college transcripts (Burns et al, 2019). It was assured that dual credit students would qualify for these adjustments and adaptations, considering that the high schools in Illinois were being temporarily shutdown throughout the state prior to many postsecondary institutions making the call the shutdown the campus.

Since the updating of dual credit policies upon the passing of new Illinois legislature in 2018, Illinois high schools and their partner community colleges have increased enrollment for students receiving instruction through dual credit courses (Smith, 2018). However, due to the COVID-19 emergency, various dual credit policy compliance issues have arisen between high schools and higher education institutions (HEI). The Illinois State Board of Education (ISBE) strongly suggested that high schools and their partner HEIs collaborate on local procedures to support dual credit students as thoroughly as possible - with little to no disruption of the course expectations and rigor (ISBE, 2020). The experiences in Illinois have implications for dual credit policies and procedures nationwide.

\section{INSTRUCTIONAL MODALITY COMPLIANCE}

One of the primary issues disrupting the scholarly studies of dual credit students is the lack of accessibility to online infrastructures, hindering a dual credit student's ability to continue their coursework in alignment with the college standards and expectations. Issues of instructional modality compliance begin 
when students and/or dual credit instructors do not have access to remote learning materials such as internet, laptops, or a designated online instructional platform. The American Library Association recognizes the "critical need for access to library and information resources, services, and technologies by all people, especially those who may experience economic distress, cultural or social isolation, physical or attitudinal barriers, housing status, barriers to equal education, and employment" (Huffman et al., 2019, p. 87). HEIs must resolve these instructional compliance issues with their high school partners as promptly as possible to avoid further disruption of the dual credit curriculum. HEIs and their high school partners must determine the interventions needed for all persons involved with dual credit coursework during the shift to remote learning. These supports may include the HEI lending laptop computers to all dual credit students and instructors at the high school level.

In addition, high school instructors who have never been trained in remote teaching have been contacting their HEI department liaisons, expressing their dismay and stress over teaching through an online platform (Giazzoni et al., 2020). Prior to COVID-19, high school dual credit instructors lacked sufficient training and proficiency in delivering remote instruction-a professional development topic often offered to professors teaching on a college campus (Mehta et al., 2019, p. 65). This suggests that dual credit students may not receive the quality of education and content rigor essential in college-level coursework (Giazzoni et al., 2020). Some institutions, such as Indiana's Ivy Tech Community College (ITCC), are instructing their dual credit enrolled students to take direction from their high school; the college will supplement gaps individually to dual credit students who were adversely harmed by remote learning during COVID-19 school closures (ITCC, 2020). This is a more simplistic solution that HEIs, regardless of location, could implement without harming the relationship with their partnering high schools. This procedure would allow high schools to take full ownership and responsibility for their adolescent students who may need more guidance compared to the traditional college student.

When providing this additional guidance, high school leaders and instructors must mindfully adapt their instruction and assessments for use with multiple electronic devices and access points if they are not offering institutionally provided devices to their dual credit students (Huffman et al., 2019). Kalir and Dillon (2020) stated that in order for learners to practice more responsible and ethical digital literacy in school for academic interest and civic advocacy, educators must participate in their own ethical and equity-oriented professional learning. In this scenario, digital literacy is defined as, "being able to 
use information and communication technologies to find, evaluate, create, and communicate information that requires both cognitive and technical skills" (Wright, 2013, p. 1). Dual credit HEI liaisons have been discussing how their high school instructional partners are expressing dismay and stress over various components such as having to learn an entirely new method of teaching, having to transfer their entire curriculum into a remote format, being expected to work from home in an environment that is not conducive for hands-on or project-based learning, in addition to not having a background in ethically utilizing digital literacy adaptations (Giazzoni et al, 2020). According to Giazzoni and colleagues (2020), HEIs are adopting various strategies in dual credit classes including, but not limited to:

- adding the HEI liaison as the main course instructor

- adding the HEI liaison as a collaborator to the online course

- providing specific dates and times for dual credit instructors to meet virtually with a technology professional and the HEI liaisons in developing effective virtual instructional methods

- HEI liaisons providing supplemental supports to dual credit instructors to add to their new online course platform.

Unfortunately, these innovative methods and strategies for curriculum design and instructional presentation are being prepared by educators with little or no professional development and training for remote learning. The increase in online learning is requiring educators to develop teaching skills and competencies beyond their subject matter knowledge. Educators are now facing more challenges and pressure such productively employing rapidly changing technologies and effectively incorporating appropriate teaching methods into an increasingly diverse environment (Martins \& Ungerer, 2017). Both HEIs and high schools must be accountable for the quality of instruction being provided to students if their dual credit students are expected to pay tuition but they earn grades with little to no support or flexibility to meet their remote learning needs. If flexible policy adaptations for dual credit students are not provided, both HEIs and high schools may be held liable in court for collecting tuition while granting failing grades to students during the COVID-19 emergency.

To mitigate these problems in the future, HEIs must allot specific funds to support dual credit students and the professional development of their dual credit instructors. For example, the Louisiana Dual Enrollment Task Force obtained \$5.5 million of their governor's proposed budget for the support and funding of teacher training to deliver college courses within dual enrollment programs in addition to funding mobile labs for community colleges (Board of 
Regents, 2020). An established statewide dual credit task force could provide an important advocacy voice to seek and secure funds directly related to dual credit programs. The funds could then be used to provide dual credit students and instructors with the tools necessary to be successful during their remote learning experiences.

\section{CONCLUSION}

Many high schools defer to their HEI partners as the final decisionmaker for dual credit procedures. However, when considering the COVID-19 pandemic and the wide array of decisions that HEIs are making regarding their college students, high schools must be given more autonomy to meet the needs of their dual credit high school students-and not base their decisions in sole alignment with their HEI partners' COVID-19 academic policy adaptations and responses. In response to COVID-19, high school administrators must take the lead when selecting and applying policy changes to their dual credit programs.

High school administrators should also encourage additional funds to be allocated and utilized for updated professional training in online instruction for dual credit faculty and staff. Training in online instruction will remain key to educational success, especially since stay-at-home orders for many states, like Illinois, are continuing throughout the $2020-2021$ academic year. The year 2020 has become an opportunity for educational experimentation, where radical exploration of the knowledge, pedagogy, relationship between mind and body, and between the self and society that might be required to live in the complexity of current conditions (Facer, 2019). Although this global pandemic is a time of trouble, it is also a time of creativity, generosity, and exploration in new ways of education.

\section{REFERENCES}

Board of Regents State of Louisiana. (2020, February). Dual enrollment task force recommends universal access to college in high school. Board of Regents State of Louisiana. https://regents.la.gov/dual-enrollment-taskforce/

Burns, K., Ellegood, W., Bernard-Bracy, J., Duncan, M., \& Sweeney II, D. (2019). Early college credit programs positively impact student success. Journal of Advanced Academics, 30(1), 27-49. https://doi.org/10.1177/1932202X18801274 
Facer, K. (2019). Storytelling in troubled times: What is the role for educators in the deep crises of the $21^{\text {st }}$ century? Literacy, 53(1), 3-13. https://doi.org/10.1111/lit.12176

Giazzoni, M., Hubbard, A., Nash, D., Kowallis, B., Stetter, T., \& Taylor, J. (2020, April 7). NACEP round table discussion on COVID-19 [Conference session]. National Alliance of Concurrent Enrollment Partnerships, Zoom Session. http://www.nacep.org/events/nacep-liveround-table-discussion-on-covid-19-part-2/

Huffman, S., Shaw, E., \& Loyless, S. (2019). Ensuring ethics and equity: Policy, planning, and digital citizenship. Education, 140(2), 87-99.

Illinois Board of Higher Education, Illinois Community College Board, \& Illinois State Board of Education. (2020). Dual credit guidance. https://ibhe.org/pdf/Join_Dual_Credit_Guidance_During_Suspension_of In-Person_Instruction-IBHE_\%20ISBE\%203.27.2020.pdf

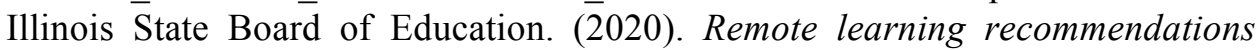
during COVID-19 emergency. https://www.isbe.net/Documents/RLRecommendations-3-27-20.pdf

Ivy Tech Community College. (2020, April). COVID-19 (coronavirus) update. https://www.ivytech.edu/coronavirus.html

Kalir, J. R. \& Dillon, J. (2020). Educators discussing ethics, equity, and literacy through collaborative annotation [In press]. In K. Hawley (Ed.), Ethical dimensions in teaching digital literacy. Rowman \& Littlefield.

Martins, N. \& Ungerer, L. M. (2017). Virtual teaching dispositions in an open distance learning environment: Origins, measurement and impact. Africa Education Review, 14(2),

156-173. https://doi.org/10.1080/18146627.2017.1294971

Mehta, R., Henriksen, D., \& Rosenberg, M. (2019). It's not about the tools: Edtech training needs to go beyond specific tools and instead enable teachers with an adaptable, creative mindset. Educational Leadership. 76(5), 64-69.

Office of Postsecondary Education. (2020). Guidance for interruptions of study related to Coronavirus (COVID-19). Federal Student Aid U.S. Department of Education. https://ifap.ed.gov/electronicannouncements/030520Guidance4interruptionsrelated2CoronavirusCOV ID19 
Smith, A. (2018, January 23). Rural recruiting problems: A recent accreditation policy has many colleges - particularly in rural areas - struggling to find qualified instructors to teach popular dual-credit courses for high school students. Inside Higher $E d$. https://www.insidehighered.com/news/2018/01/23/colleges-and-statesscramble-comply-instructor-credential-rules-dual-credit-courses

Wright, J. (2013, June 18). ALA task force releases digital literacy recommendations. ALA News. http://www.ala.org/news/pressreleases/2013/06/ala-task-force-releases-digital-literacyrecommendations

ALEXANDREA HORTON, Ed.D Candidate, is an English Department Chair at Crown Point High School and Concurrent Enrollment Board Member for Purdue University Northwest. Her major research interests lie in federal and state education policy influence, policy implementation strategies, and dual credit partnerships. Email: ahorton8611@gmail.com 